\title{
INFLUÊNCIA DA QUANTIDADE DE CAULIM E DE AGENTE COMPATIBILIZANTE NO ÍNDICE DE FLUIDEZ DE COMPÓSITOS PEAD/CAULIM
}

\author{
Márcio Alves de Lima ${ }^{1}$ \\ Gilmara Brandão Pereira ${ }^{2}$ \\ Brunno José Silva de Jesus ${ }^{3}$ \\ Ezequiel de Andrade Silva ${ }^{4}$ \\ Cirlene Fourquet Bandeira ${ }^{5}$ \\ Sérgio Roberto Montoro ${ }^{6}$
}

Resumo: Na maioria das vezes os polímeros puros não apresentam as propriedades para atendimento das especificações técnicas, as quais a aplicação final requer. Tais propriedades podem ser aprimoradas através do emprego de cargas minerais e agentes compatibilizantes no processamento de compósitos de matrizes poliméricas reforçados com cargas minerais. O Caulim é um mineral global usado principalmente como pigmento para melhoria da aparência e funcionalidade do papel e tintas, como material de reforço para plásticos, como matéria-prima de cerâmica, como componente de tijolos refratários e produtos de fibra de vidro. No presente trabalho foram caracterizados compósitos poliméricos de PEAD reforçados com Caulim. Foram caracterizadas 4 famílias de compósitos onde foram variadas as proporções de carga mineral e agente compatibilizante. Foi possível constatar que o índice de fluidez apresentou uma pequena redução na maioria dos experimentos em relação ao PEAD puro. Pode-se constatar também a importância do agente compatibilizante na propriedade de índice de fluidez.

Palavras-chave: Compósitos; PEAD; Caulim; Índice de Fluidez; Compatibilizante.

\footnotetext{
${ }^{1}$ Mestrado Profissional em Materiais/UniFOA, Brasil. E-mail: marcioalvestna@hotmail.com,

2 Mestrado Profissional em Materiais/UniFOA, Brasil. E-mail: brandaoconsultoria.treinamento@gmail.com,

3 Mestrado Profissional em Materiais/UniFOA, Brasil. E-mail: brunnodorandia@hotmail.com,

${ }^{4}$ Mestrado Profissional em Materiais/UniFOA, Brasil. E-mail: zecandrade@yahoo.com.br,

5 Mestrado Profissional em Materiais/UniFOA, Brasil. E-mail: cirlenefourquet@yahoo.com.br,

${ }^{6}$ Mestrado Profissional em Materiais/UniFOA, Brasil. E-mail: sergio.montoro@foa.org.br.
} 